\title{
Self-propagating high-temperature synthesis of titanium borides
}

\author{
S K ROY, A BISWAS and S BANERJEE \\ Metallurgy Division, Bhabha Atomic Research Centre, Bombay 400085, India \\ MS received 17 July 1993
}

\begin{abstract}
The application of self-propagating high-temperature synthesis (SHS) to prepare a few borides of titanium was investigated. Using the plane wave propagation mode, the synthesis of titanium borides in the cold-pressed cylindrical specimens of the component powder mixtures was effected and was studied as a function of boron content in the initial mix and the specimen size. SHS reaction in compacts having diam. of $6 \mathrm{~mm}$ or less and high bulk density could not be initiated and/or sustained and was considered to be a result of rapid heat dissipation.
\end{abstract}

Keywords. SHS; titanium borides.

\section{Introduction}

Synthesis of advanced materials, refractory ceramics and intermetallic compounds has recently generated significant interest. An extremely simple and economical method for producing these materials is the self-propagating high-temperature synthesis (SHS). SHS is based on exothermic reactions between components with directional combustion. Chemical reactions that are sufficiently exothermic can transform spontaneously into products when initiated and will propagate through the reactants' mixture in the form of a combustion wave. The final product is obtained progressively without requiring additional heat. Two variants of this process are recognized, namely plane wave propagation mode and the thermal explosion mode. The plane wave propagation mode involves triggering the reaction by rapid heating of one end of the specimen. The reaction zone propagates as a wave front through the sample, driven by the exothermicity of the reaction. In the thermal explosion mode, the compacted reactant powders are heated up at a constant rate until the reaction is initiated uniformly throughout the sample. This technique is more suited to reactions with low exothermicity.

SHS as a new method for synthesis of materials was first utilized by Merzhanov et al (1967). Since then, a substantial and continuously growing research effort is directed in this field and a large variety of materials and technologies have emerged (Munir 1988). These materials include borides, carbides, nitrides and silicides of metals, composites, intermetallics and cuprate superconductors. According to Merzhanov (1990), SHS processing techniques can be divided into six types. These are: SHS process of manufacturing the blanks and powders, SHS sintering, SHS powder compacting, SHS metallurgy, SHS welding, and the production process of the SHS coatings. Using these techniques of SHS processing, it is possible to obtain a wide spectrum of materials - powders, monoliths and coatings.

Self-propagating high-temperature synthesis has many attractive features: good energy efficiency, cost effectiveness, short processing time and high product purity. When SH synthesis takes place between elemental reactants, it becomes easy to 
control the product composition. Processing by SHS offers the possibility of simultaneous product formation and consolidation.

The SHS process attracted widespread attention from specialists in various areas due both to the value of the materials produced and to the very interesting scientific and technological problems to be solved in order to understand and control the process. Detailed technical reviews have been forwarded by Crider (1982), Munir (1988), Munir and Anselmi-Tamburini (1989), Merzhanov (1990) and Hlavacek (1991).

The objective of the present research was to evaluate the method and to study the feasibility of producing a few refractory binary compounds, with or without preheating, using the technique of self-propagating high-temperature synthesis in plane wave propagation mode. In this investigation, the $\mathrm{SH}$ synthesis of borides was undertaken because boron combines readily with other elements and because the binary metal borides comprise a family of materials which is witnessing growing scientific and technical interest. Binary metal borides are large in number and are rendered even more numerous by a wide range of atomic ratios. There are also many so-called non-stoichiometric borides. These borides possess a number of noteworthy properties which include high strength and hardness, high melting point, superior wear resistance, chemical inertness and electrical conductivity of metallic order. The system Ti-B was chosen because of interest, both scientific and technological, in these borides for refractory, abrasive and electrochemical applications. The projected applications of titanium diboride are manifold: as a matrix material in hard metal cutting tools, in the production of vacuum metallizing boats, as grain refining agent in aluminium, in nuclear industry as neutron absorbing material, and as cathode in the production of metallic aluminium by electrolysis in the Hall and Heroult cell.

The condensed phase diagram of the titanium-boron system was studied by Rudy

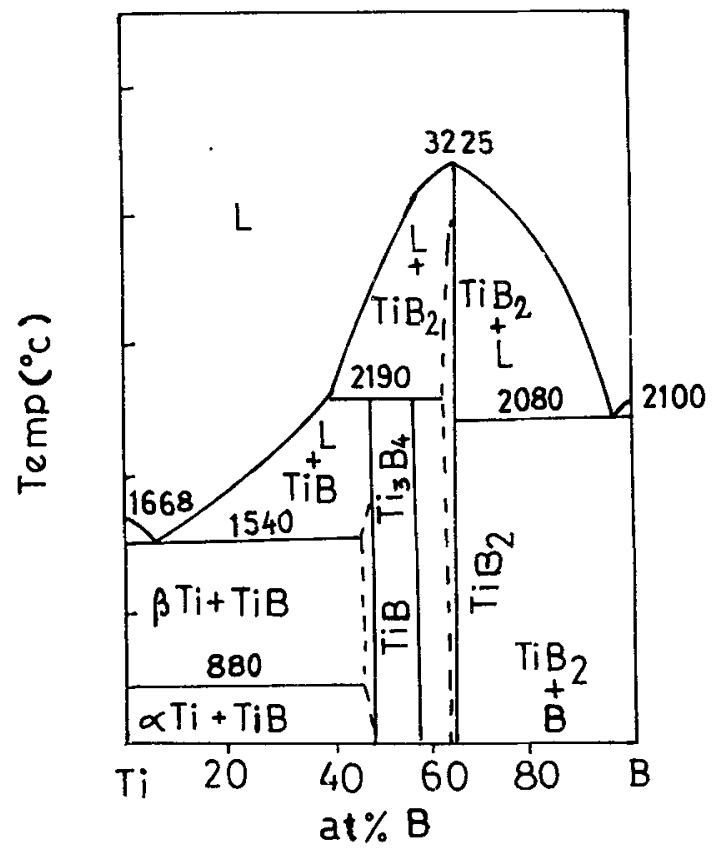

Figure 1. Phase diagram of the Ti-B system (Murray et al 1986). 
and St. Windisch (1966) and subsequently revised by Murray et al (1986). The revised diagram is shown in figure 1 . As shown in this diagram, there are three intermetallic compounds: $\mathrm{TiB}, \mathrm{Ti}_{3} \mathrm{~B}_{4}$ and $\mathrm{TiB}_{2}$. The material $\mathrm{TiB}_{2}$ is a congruent melting compound with melting point of $3225^{\circ} \mathrm{C}$; on the other hand, under equilibrium conditions, both $\mathrm{TiB}$ and $\mathrm{Ti}_{3} \mathrm{~B}_{4}$ undergo peritectic decompositions at temperatures near $2190^{\circ} \mathrm{C}$. Occurrence of other borides in Ti-B system has also appeared in the literature. Pearson (1958) reported the occurrence of a cubic $\mathrm{NaCl}$-type $\mathrm{Ti}_{2} \mathrm{~B}$ phase, which Aronsson et al (1965) subsequently identified as a ternary phase containing C, $\mathrm{O}$ or $\mathrm{N}$. $\mathrm{Ti}_{2} \mathrm{~B}_{5}$ was identified by Goldschmidt (1967) as a hexagonal phase undergoing peritectic decomposition at $2100^{\circ} \mathrm{C}$. The boride $\mathrm{Ti}_{1.87} \mathrm{~B}_{50}$ has also been reported to exist (Calvert 1990).

Although self-propagating high-temperature synthesis of titanium diboride has been investigated by Azatyan et al (1980), Zavitsanos and Morris (1983), Holt et al (1985) and Rogachev et al (1987), there is, however, a general lack of consistent data on the processing of other borides in this system. Moreover, all the earlier researches mentioned above were conducted in argon. Hence, it was decided to study the synthesis of a wide range of borides of titanium under dynamic vacuum conditions.

\section{Experimental procedure}

The reagents used in the synthesis were elemental powders of $\mathrm{Ti}$ and $\mathrm{B}$ prepared indigenously in the Metallurgy Division (Nair et al 1992). The boron used in this work was amorphous 'brown' boron obtained by the electrolysis process and was $98.6 \%$ pure. Both the powders had particles whose size was below $1 \mu$.

Figure 2 depicts schematically the experimental procedure used to react titanium and boron in this study. Powders were weighed out in the desired stoichiometric ratios corresponding to the compounds $\mathrm{TiB}, \mathrm{Ti}_{3} \mathrm{~B}_{4}, \mathrm{TiB}_{2}, \mathrm{Ti}_{2} \mathrm{~B}_{5}$ and $\mathrm{Ti}_{1.87} \mathrm{~B}_{50}$ and were dry mixed in a ball mill for $2 \mathrm{~h}$ to assure a homogeneous mixture. Cylindrical compacts were formed by uniaxial cold pressing in hardened steel dies. The compacts were formed in different sizes having diam. 6,9,10 and $14 \mathrm{~mm}$ and lengths varying between 5 and $15 \mathrm{~mm}$. A hole $3 \mathrm{~mm}$ diam. and $3 \mathrm{~mm}$ deep was drilled into one end of each of the specimens into which an insulated type $\mathrm{K}$ thermocouple was introduced to monitor the temperature excursion during synthesis and to record the same on a strip-chart recorder. SH synthesis of various Ti borides was performed in a graphite crucible ( $20 \mathrm{~mm}$ diam.: $8 \mathrm{~cm}^{3} \mathrm{vol}$.) inside a quartz reactor which is connected to a rotary vacuum pump. For heating the specimens before ignition, when desired, a furnace with Kanthal A-1 heating element was used. The experimental SHS station is shown schematically in figure 3 .

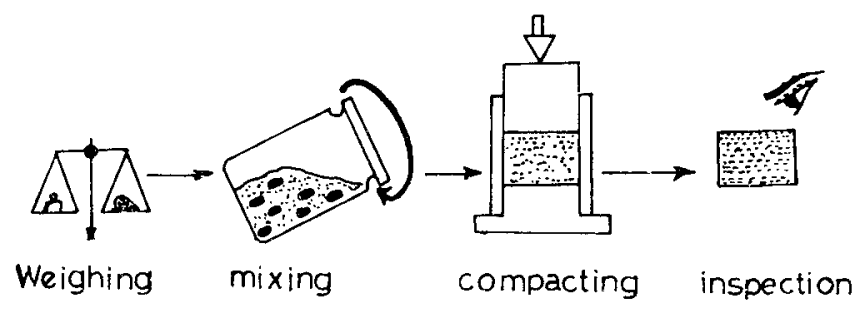

Figure 2. Experimental procedure used to react titanium and boron. 


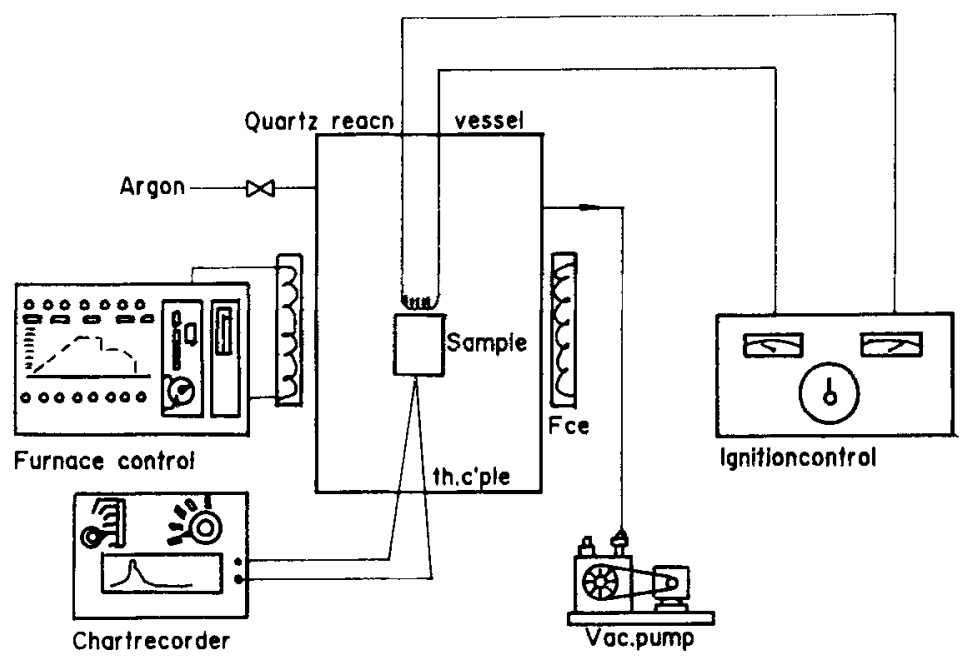

Figure 3. Experimental station for self-propagating high-temperature synthesis of titanium borides.

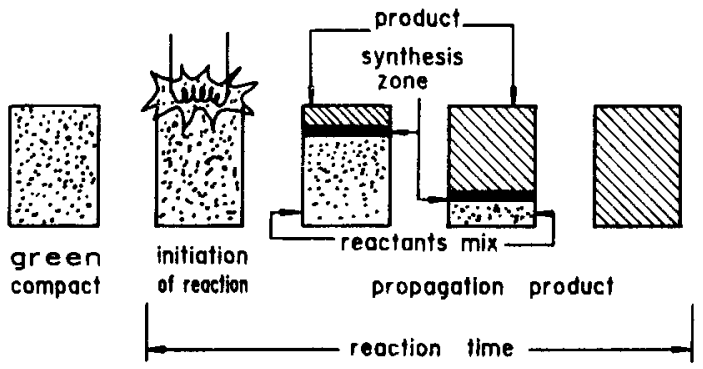

Figure 4. Plane wave propagation during SHS reaction in the Ti-B system.

The reaction was started on the top of a compact by exploding a Kanthal A-1 spiral by passing large current through it. Once initiated, the exothermic reaction became self-sustaining and propagated through the compact in the form of a narrow luminous synthesis zone. The reactants were converted to products as the combustion front advanced, as shown schematically in figure 4. All the synthesis reactions were carried out under a dynamic vacuum condition. Final products were analysed by $\mathrm{X}$-ray diffraction and microscopic methods.

\section{Results and discussion}

Figure 5 is a typical temperature-time curve showing the sudden increase in temperature due to combustion and the subsequent gradual decrease in temperature as the product cooled. These stoichiometric reactions proceeded very rapidly in an almost explosive manner, with the total specimen of about $2 \mathrm{~g}$ being reacted entirely in $0.3 \mathrm{sec}$ approximately. Figure 5 depicts the thermal excursions during the formation of the compounds $\mathrm{TiB}$ and $\mathrm{TiB}_{2}$ by the $\mathrm{SH}$ synthesis technique operating in the plane wave propagation mode. Both these reactions behaved similarly although the peak 


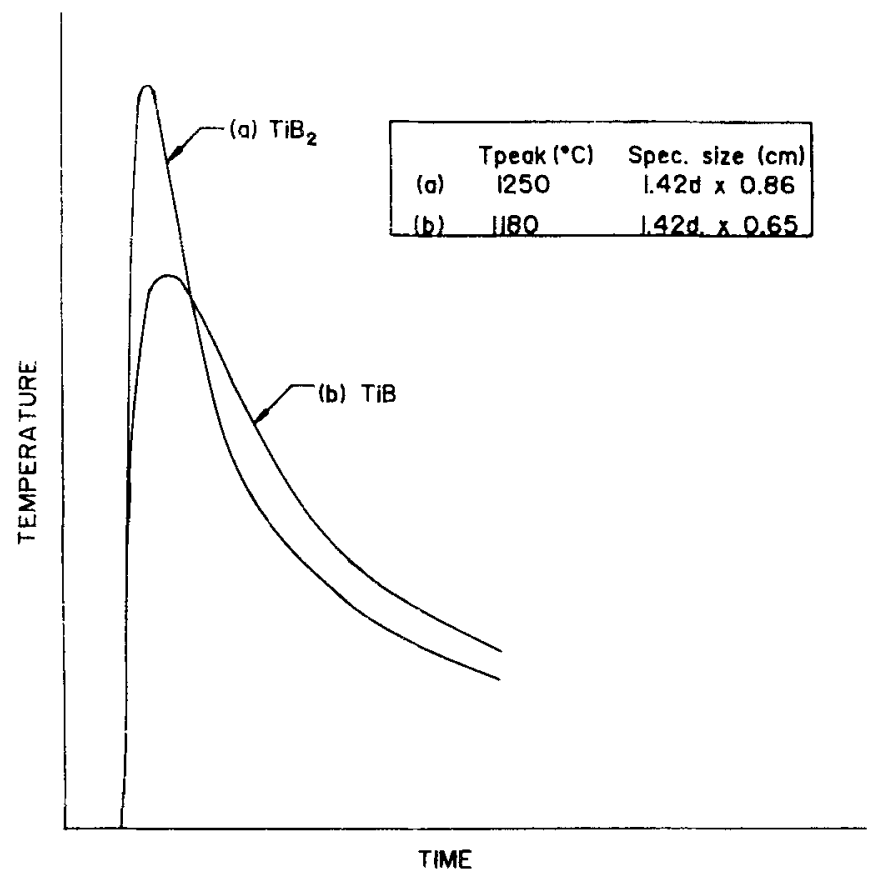

Figure 5. Temperature-time curves for the formation of $\mathrm{TiB}_{2}$ and $\mathrm{TiB}$ by self-propagating high-temperature synthesis.

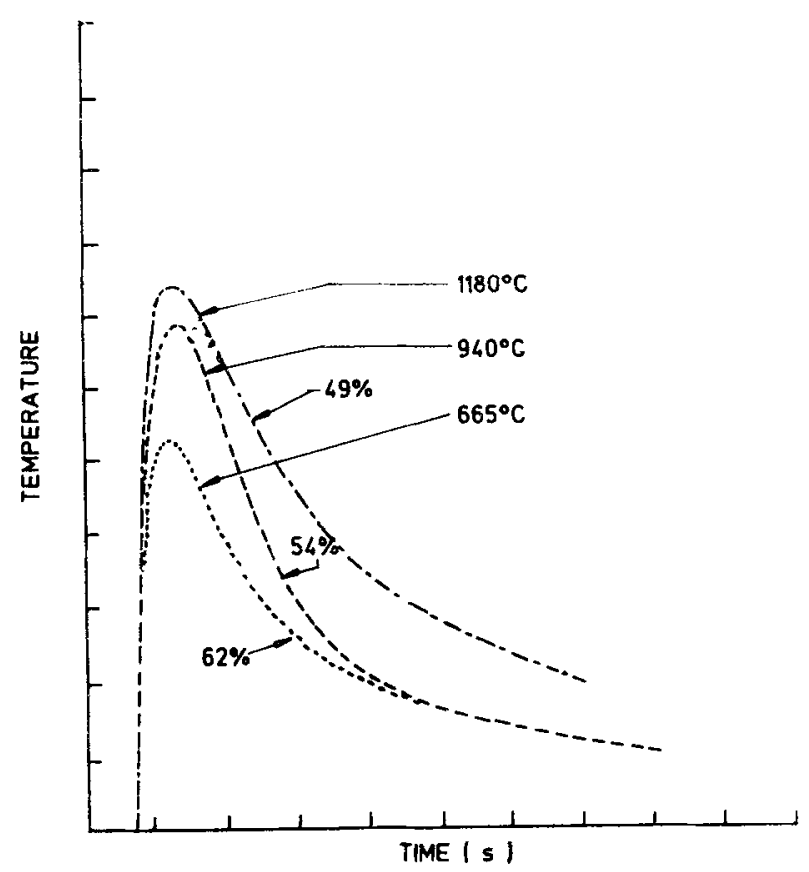

Figure 6. Effect of initial porosity on the combustion behaviour of equiatomic mixture of titanium and boron. 
temperature was lower for the TiB synthesis. During the SH synthesis of 1.B, it was observed that within the range of porosity studied, the peak temperature recorded was lower as the porosity increased and varied by about $500^{\circ} \mathrm{C}$ when initial porosity changed from 49 to $61 \%$. These results are reflected in the temperature profiles shown in figure 6. Under these conditions, however, steady combustion took place. Similar trends were noted in $\mathrm{TiB}_{2}$ synthesis also.

It is noticed in figure 5 that the peak temperatures, as measured with a thermocouple, were much lower than the adiabatic temperatures for these systems and the peak temperatures for $\mathrm{TiB}_{2}$ is higher than that of $\mathrm{TiB}$ although the adiabatic temperatures for $\mathrm{TiB}_{2}$ and $\mathrm{TiB}$ are $3190 \mathrm{~K}$ and $3350 \mathrm{~K}$ respectively. The precise reason for such behaviour is not known at present. However, it is supposed to be caused by a variety of experimental conditions which include large heat losses by radiation, positioning of the thermocouple near the end of the specimen, large response time of the temperature sensor, etc. Besides these reasons, it is believed that this lowering was caused by a deceleration of the reaction when it was approaching the lower end of the specimen. The results of SH synthesis of various borides attempted in this study are given in table 1 . It was observed that at a sufficiently high boron content (the synthesis of $\mathrm{Ti}_{1.87} \mathrm{~B}_{50}$ ), no reaction took place in the system, even when ignition was initiated with a thin $(\mathrm{Ti}+2 \mathrm{~B})$ compact and was preheated up to $550^{\circ} \mathrm{C}$. Boron has the density of $2.34 \mathrm{~g} \mathrm{~cm}^{-3}$, i.e. it occupies 0.923 volume fraction of the $\mathrm{Ti}$ and $\mathrm{B}$ mixture corresponding to the stoichiometry $\mathrm{Ti}_{1.87} \mathrm{~B}_{50}$. Considering the geometry of packing of $\mathrm{Ti}$ and $\mathrm{B}$ particles in this case, it becomes evident that heat transfer from a $\mathrm{Ti} / \mathrm{B}$ interface participating in the reaction will have to take place through a wide region formed by $\mathrm{B}$ particles only. Low thermal conductivity of boron and its relatively high heat capacity could cause interruption of heat transfer and consequent failure of the $\mathrm{SH}$ reaction in this compact. The specimens of $(2 \mathrm{Ti}+5 \mathrm{~B})$ could initiate and sustain the $\mathrm{SH}$ reaction only when preheated to $350^{\circ} \mathrm{C}$.

It was observed that in vacuum the propagation of planar synthesis wave in the Ti-B system was governed by the size of the specimen, and no reaction could be initiated and/or sustained when the specimen diam. was $6 \mathrm{~mm}$. This failure to carry out boride synthesis in small sized compacts could be attributed to increased radial heat losses whereby the total heat generated by the specific chemical reaction fell below the value for heat lost by the specimen.

The pressed compacts in which the SH reaction proceeded from one end to the other underwent a considerable volume expansion. Although the product integrity

Table 1. Experimental conditions and product compositions of the SH reactions in the $\mathrm{Ti}-\mathrm{B}$ system.

\begin{tabular}{|c|c|c|c|c|}
\hline Stoichiometry & $\begin{array}{l}\mathrm{Ti} / \mathrm{B} \text { ratio } \\
\text { (atomic) }\end{array}$ & $\begin{array}{l}\text { Pre-heating } \\
\left({ }^{\circ} \mathrm{C}\right)\end{array}$ & $\begin{array}{l}\text { Nature of the } \\
\text { reaction }\end{array}$ & Phases \\
\hline $\begin{array}{l}\mathrm{Ti}_{1 \cdot 87} \mathrm{~B}_{50} \\
\mathrm{Ti}_{2} \mathrm{~B}_{5}\end{array}$ & $\begin{array}{l}0 \cdot 037 \\
0 \cdot 4\end{array}$ & - & $\begin{array}{l}\text { Nil } \\
\text { Plane wave } \\
\text { propagation } \\
\quad \text { (PWP) }\end{array}$ & $\underset{\text { (major) }}{\overline{\mathrm{TiB}_{2}}}$ \\
\hline $\begin{array}{l}\mathrm{TiB}_{2} \\
\mathrm{Ti}_{3} \mathrm{~B}_{4} \\
\mathrm{TiB}_{4}\end{array}$ & $\begin{array}{l}0.5 \\
0.75 \\
1.0\end{array}$ & $\begin{array}{l}\text { RT } \\
\text { RT } \\
\text { RT }\end{array}$ & $\begin{array}{l}\text { PWP } \\
\text { PWP } \\
\text { PWP }\end{array}$ & $\begin{array}{c}\mathrm{TiB}_{2} \\
2 \text { phases } \\
\text { TiB }\end{array}$ \\
\hline
\end{tabular}



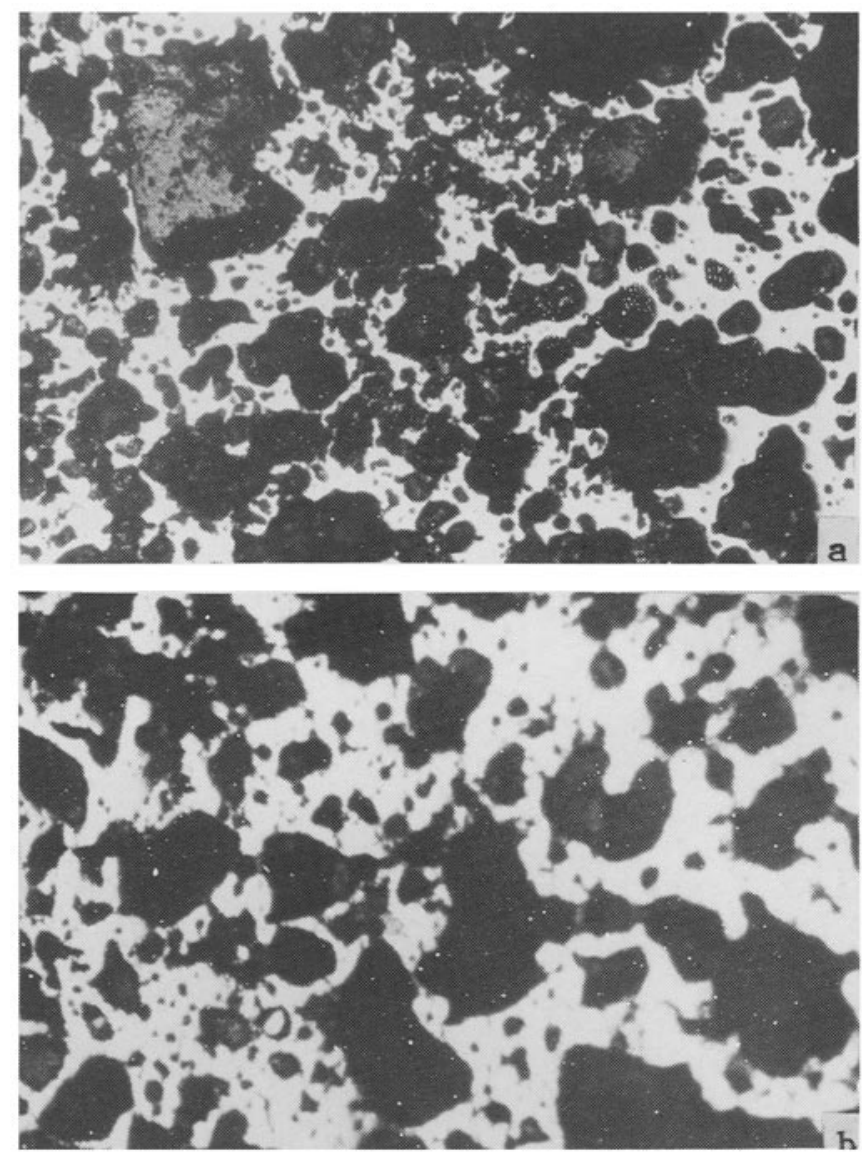

Figure 7. Optical micrographs of cross-section through (a) $\mathrm{TiB}$ and (b) $\mathrm{TiB}_{2}$ produced by SH synthesis without consolidation. Dark regions represent voids present in the reacted materials.

was maintained, the resulting samples were extremely porous with sponge-like appearance. Figure 7 illustrates typical structures of $\mathrm{SH}$ synthesized $\mathrm{TiB}_{2}$ and $\mathrm{TiB}$ as seen with an optical microscope. The dark areas in the micrograph respresent voids. The occurrence of the pores could be ascribed to four general sources (Munir and Wang 1990). These are: (a) the initial porosity of the powder mixtures in pressed compacts prior to the reaction; (b) the difference in the molar volumes between the reactants and the products; (c) the formation of gases in conjunction with the reaction, principally the vaporization of the impurity phases and their subsequent expansion, entrapment or expulsion; and (d) thermal migration of voids due to high temperature gradient in the combustion mode. Indeed a considerable increase in the dimensions of the SHS product compared with the reactants was often noticed. Because of the impure nature of the boron employed in this investigation, it is surmised that the escape of the impurity phase as a gas contributed significantly to the product porosity.

The extent of reaction taking place during self-propagation in vacuum and the quality of the end products were assessed by X-ray diffraction technique. The results of this study are depicted in figure 8 . It is readily seen that no unreacted boron or 


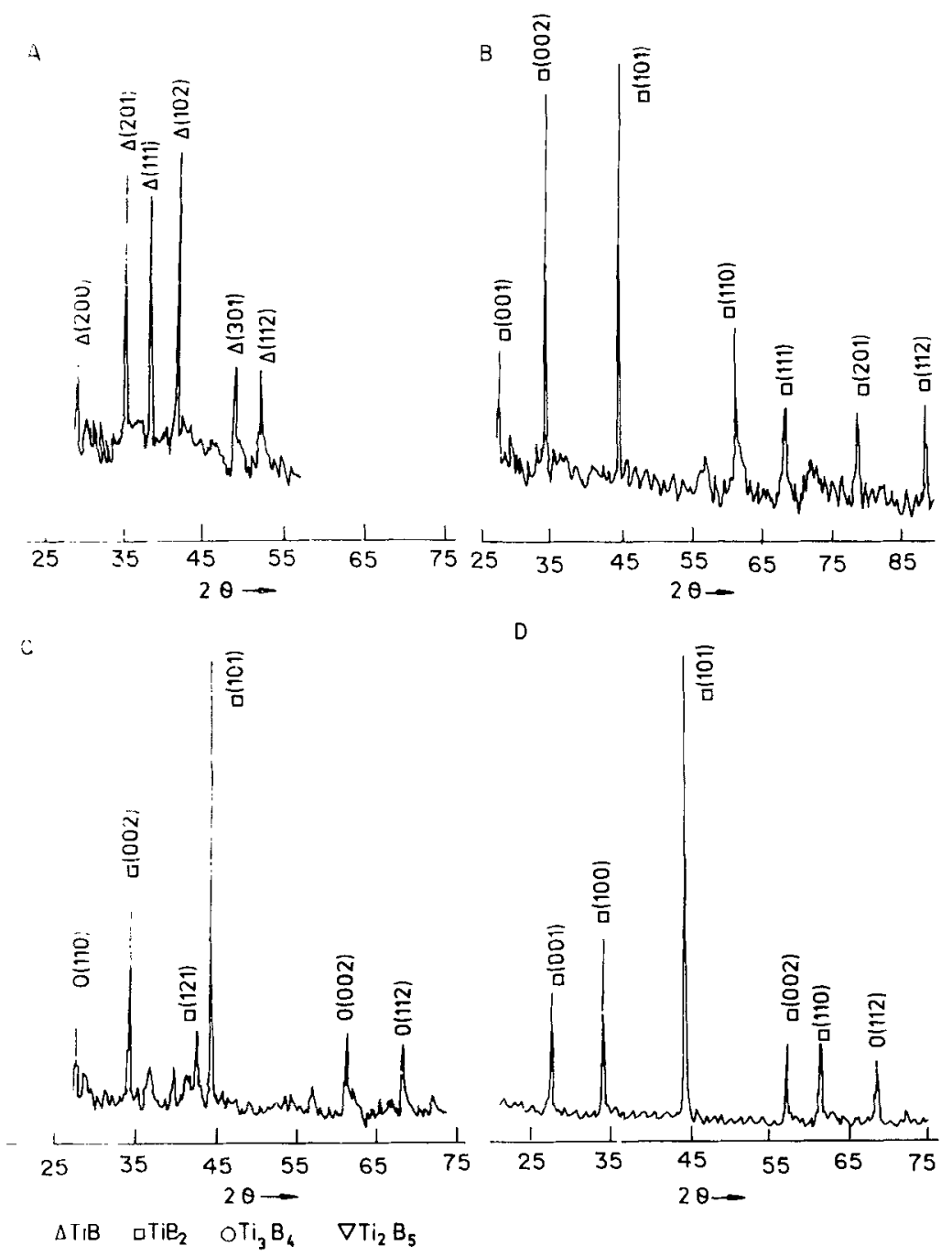

Figure 8. X-ray diffractograms of the products obtained by the SHS reactions in the Ti-B system contanning $\mathrm{Ti}$ and $\mathrm{B}$ in the atomic ratio of (A) $1: 1$, (B) $1: 2$, (C) $3: 4$ and (D) $2: 5$.

titanium was present in the products obtained by SH synthesis in vacuum; in other words, the respective reactions could be carried out to completion. It is also seen from the nature of these diffractograms that the products were well-formed crystals produced from the $\mathrm{Ti}$ and $\mathrm{B}$ mixtures of the designed stoichiometry. An examination of the diffraction patterns of the various borides of titanium revealed that while the compounds $\mathrm{TiB}$ and $\mathrm{TiB}_{2}$ formed readily and were phase pure, the $\mathrm{SH}$ reactions in the compacts of $(3 \mathrm{Ti}+4 \mathrm{~B})$ produced two phases, namely $\mathrm{TiB}_{2}$ and $\mathrm{Ti}_{3} \mathrm{~B}_{4}$, and broadly confirms the phase relationship expressed in the $\mathrm{T}_{\mathrm{i}}-\mathrm{B}$ equilibrium phase diagram. The diffraction patterns of both $\mathrm{TiB}_{2}$ and $\mathrm{TiB}$ evidenced that the most intense peaks of these compounds shifted to higher angles indicating the formation of solid solutions. The attempt to synthesize $\mathrm{Ti}_{2} \mathrm{~B}_{5}$, however, did not succeed and as the result of the propagation of combustion wave, the principal phase that formed was $\mathrm{TiB}_{2}$. 
The results of the present investigation put forward the evidence that it was possible to initiate and sustain the plane wave propagation mode of combustion reactions between particles of elemental boron and titanium in various ratios in vacuum and synthesize a number of borides. The products, especially $\mathrm{TiB}_{2}$ and $\mathrm{TiB}$, were obtained in well-crystallized and single-phase conditions, when synthesized in a dynamic vacuum. Earlier, it was reported by Merzhanov (1981) that combustion could occur in vacuum when the combustion temperatures were high and the fugacities were extremely low. In the binary system of titanium and boron, the enthalpy of reaction is quite high (for evample $-\Delta H_{298}^{0}=70 \mathrm{kcal} / \mathrm{mol}$ for $\mathrm{TiB}_{2}$ synthesis) but the calculated vapour pressure of $\mathrm{Ti}$ at the adiabatic temperature is also substantial (about $0 \cdot 1$ atmosphere at $3190 \mathrm{~K}$ ). It is then expected that a substantial loss of titanium would occur with the result that combustion initiation-propagation might be affected or if it occurs, the products will not be monophasic. The results of the present investigation show that the principal characteristics of the gasless combustions are preserved in cases of reaction in the $\mathrm{Ti}-\mathrm{B}$ system in vacuum. It appears that some other factors exert considerable influence in determining the course of $\mathrm{SH}$ reactions and need to be taken into consideration while elucidating the course of synthesis. Further researches are needed to explain their role.

\section{Conclusion}

It was established that elemental titanium and boron could react in vacuum under plane wave propagation mode of self-propagating high-temperature synthesis to produce a few borides.

The borides $\mathrm{TiB}_{2}$ and $\mathrm{TiB}$ were formed in well-crystallized and phase pure condition.

The method described provides a simple and quick means for synthesizing refractory $\mathrm{Ti}$ borides at ambient temperatures.

\section{References}

Aronsson B, Lundstorm T and Rundquist S 1965 Borides, phosphides and silicides (London: Methuen \& Co. Ltd.) Ch. 2, pp. 10-31

Azatyan T S, Maltsev V M, Merzhanov A G and Seleznev V A 1980 Comb. Exp. Shock Waves 16163

Calvert L 1990 JCPDS grant-in-aid report 1976 JCPDS-ICDD 29-1356

Crider J F 1982 Ceram. Engg. Sci. Proc. 3519

Goldschmidt H I 1967 Interstitial alloys (London: Butterworths) Ch. 6, pp. 254-295

Hlavacek V 1991 Bull. Am. Ceram. Soc. 70240

Holt J B, Kingman D D and Bianchini G M 1985 Mater. Sci. Engg. 71321

Merzhanov A G 1981 New problems in the theory and practice of combustion processes, in Problems in chemical kinetics (ea.) N Emanuel (Moscow: MIR Publ.) p. 74

Merzhanov A G 1990 Self-propagating high-temperature synthesis: twenty years of search and findings, in Combustion and plasma synthesis of high temperature materials (eds) Z A Munir and J B Holt (New York: VCH Publ.) p. 1

Merzhanov A G. Shkiro V M and Borovinskaya I P 1967 USSR Author's certificate no 255221, Appl. 1170735, Invest. Bull.

Munir Z A 1988 Bull. Am. Ceram. Soc. 67342

Munir Z A and Anselmi-Tamburini U 1989 Mater. Sci. Rep. 3277

Munir Z A and Wang L L 1990 Proc. Ist US-Japan workshop on combustion synthesis (eds) Y Kaieda and J B Holt (Tokyo: National Research Institute of Metals) p. 123 
Murray J L, Liao P K and Spear K E 1986 Binary alloy phase diagrams (ed.) T D Massalski (Ohio: ASM) pp. $387-391$

Nair K U, Bose D K and Gupta C K 1992 Miner. Process. Ext. Met. Rev. 9283

Pearson W B 1958 A handbook of lattice spacings and structures of metals and alloys (New York: Pergamon)

Rogachev A S, Mukasyan A S and Merzhanov A G 1987 Dokl. Akad. Nauk. SSSR 2971425

Rudy E and Windisch St. 1966 Tech. Rept. No. AFML-TR-65-2 Wright Patterson AFB

Zavitsanos P D and Morris J R Jr 1983 Ceram. Eng. Sci. Proc. 4624 